\title{
Estimating Freight
}

Transport Activity Using

Nighttime Lights Satellite

Data in China, India and

Saudi Arabia

Hector G. Lopez-Ruiz,

Nora Nezamuddin, Reema Al Hassan

and Abdelrahman Muhsen 


\section{Acknowledgments}

The authors wish to thank the following reviewers for their input: Brian Efird, Anwar Gassim, Marie Sevenet, Jorge Blazquez and Rolando Fuentes. The authors also wish to thank Mario Morales for his work on the visual guide and Maggie Yuan Yao for her contributions to the analysis of China.

\section{About KAPSARC}

The King Abdullah Petroleum Studies and Research Center (KAPSARC) is a non-profit global institution dedicated to independent research into energy economics, policy, technology and the environment across all types of energy. KAPSARC's mandate is to advance the understanding of energy challenges and opportunities facing the world today and tomorrow, through unbiased, independent, and high-caliber research for the benefit of society. KAPSARC is located in Riyadh, Saudi Arabia.

\section{Legal Notice}

(C) Copyright 2019 King Abdullah Petroleum Studies and Research Center (KAPSARC). No portion of this document may be reproduced or utilized without the proper attribution to KAPSARC. 


\section{Key Points}

he KAPSARC Transport Analysis Framework (KTAF) estimates transport activity from freely available global data sources, satellite images and nighttime lights (NTL). It is a tool for estimating freight transport activity that can be used in models to measure the impact of an accelerated transport policy planning approach.

This paper focuses on the methodology for estimating total freight transport activity (FTA) for three countries with the objective of building on current state-of-the-art transportation modeling in three key areas:

Studying the relationship between NTL and FTA allows for an estimation of full transportation datasets for countries where only a few observation points exist or where data is unavailable.

Establishing the foundation for future work on how to use this approach in transport flow estimation (origin-destination matrices).

Determining whether this approach can be used globally, given the coverage of the satellite data used.

Figure 1. Nighttime lights 2012 - flat map.

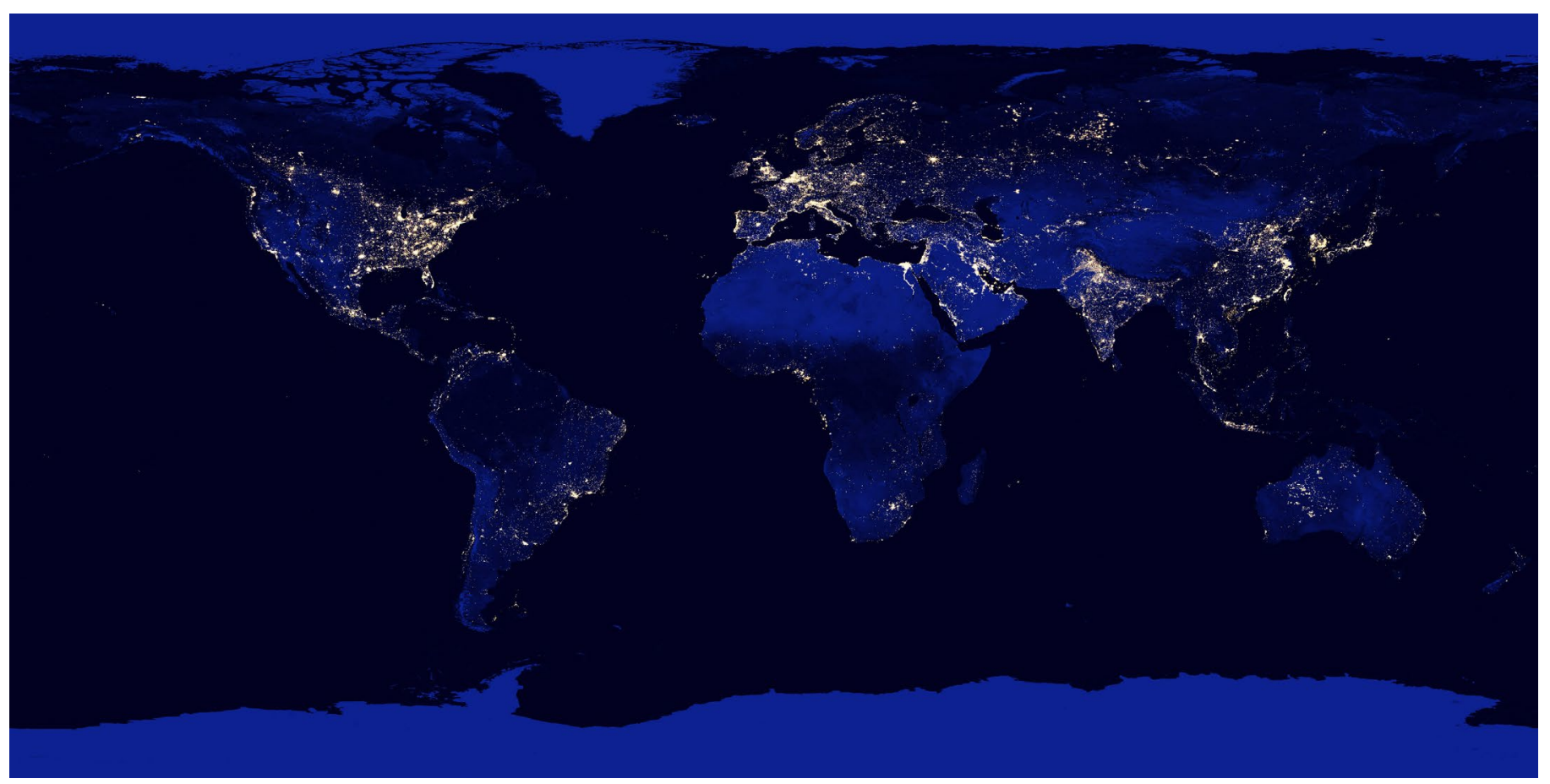

Source: NASA Earth Observatory. 


\section{Summary}

he KAPSARC Transport Analysis Framework (KTAF) is a tool based on a transport energy demand model that utilizes open-source data from nightlight and satellite images and available primary data to analyze transport policy. This paper documents the methodological work carried out for KTAF on estimating freight transport activity using open-source satellite data. It offers a simple guide on how to utilize this user-friendly approach to estimate freight transport demand.

The paper focuses on using night satellite radiometry to estimate total freight transportation activity in any city, region or country, based on the intensity of nighttime lights and their relationship with economic and human activity on the ground. China, India and Saudi Arabia were used as case studies, due to the important economic relationship between them. Saudi Arabia imports products from China and India and is a major exporter of oil to both countries.

The paper offers a solution to inadequate data access. This allows for scenario building in policy planning for transportation. This approach allows for quick estimatation of the effects of policy measures and economic changes on transportation activities at a global level. This document includes a full graphic guide on how to replicate the methodology used in this analysis. 


\section{Introduction}

E nergy demand from transportation and its environmental and economic effects has quickly become one of the focal points of policy design in major cities and regions around the world. However, planning for energy sustainability in transportation usually meets a major hurdle: the speed and precision at which transport demand scenarios and policy analysis can be delivered in order to make informed policy decisions quickly. An important component in overcoming this hurdle is linked to the availability of robust and easily available data.

The main objective of this research is to develop a framework for data acquisition and rapid transport policy simulation, evaluation and quantification based on globally available robust data that is easy to gather and to understand.

To achieve this objective, we move away from a model design based on methodological individualism (use of a representative agent) in order to embrace an approach that focuses on estimating transportation activity based on territorial network connections and economic reality. This approach implies being able to assess economic and human activity in different territorial units connected through infrastructural links. These represent freight transport activity (FTA) that link directly to economic and human activity. Various research projects have used the National Oceanic and Atmospheric Administration's (NOAA) nighttime lights (NTL) satellite images as a proxy for economic and human activity, starting with papers that explored the use of NTL as an economic indicator, such as the work of Elvidge et al. (1997) and their subsequent proposal to build the Night Light Development Index. In 2012, Pinkovskiy et al. used NTL to assess economic development. There have also been many papers on the link between human economic activity and the intensity of the radiance of NTL captured by satellites. Doll et al. (2006) explored mapping regional economic activity with NTL. Chen and Nordhaus (2011) proposed the use of luminosity as a proxy for economic statistics. Rybnikova and Portnov (2015) illustrate how geographic concentrations of economic activities can be reconstructed using NTL satellite measurements, and that such reconstructed data can then be used for the identification of economic and human activity clusters. Various studies were conducted in the field of transportation using an NTL-based approach to estimate flows. Shi Yu et al. (2015) carried out this type of estimation for freight transportation in China.

Our approach draws from this growing body of work and integrates the idea of using NTL as a proxy for freight transportation in three countries: China, India and Saudi Arabia. These countries were selected on the basis of their economic ties. They also allowed for the analysis of FTA estimation with NTL in countries with different economic and human activity profiles. Choosing heterogeneous countries allows us to test our approach in a variety of situations to assess if it could be applicable globally. The variability in the countries studied offered great insights into the different challenges of using NTL in FTA estimation.

Identifying these hurdles in the use of NTL as a proxy for economic activity has allowed for a clearer understanding of the use of NTL in FTA estimation, and its implications when integrating this approach within a classic analysis framework for transportation modeling.

The first section of this paper provides an overview of the relationship between FTA and NTL. A detailed methodology of how to use NTL in order 
to estimate FTA follows, as well as a discussion on the hurdles encountered in the use of NTL for FTA estimation. Finally, we identify further research possibilities in freight transport modelling using NTL. Annex 1 includes a step-by-step guide for the process detailed in the following sections. Annex 2 details the data on freight transport used for each country. Lastly, all codes used for this exercise will be made available through KAPSARC's KTAF project GitHub. This document only focuses on the process of acquiring data to be used as inputs into a classic transport model to analyze freight transportation. 


\section{Exploring the Relationship Between Freight Transport Activity and Nighttime Lights}

$F$ reight transportation activity (FTA) is closely linked to a region's economy. As regional economies evolve, so does the demand for logistics and transportation services. Variations in freight transportation depend on the structure of the economy, its vitality and its present and future organization. The fluidity of freight transportation is also an important component of regional economies and their development. As such, the interplay between transportation and economic vitality is at the heart of economic development.

However, as the share of energy demand used by transport continues to increase globally, governments have increasingly begun to address the related externalities of air pollution and greenhouse gas emissions. Moreover, the increase in freight transportation demand goes hand-inhand with a more important use of transportation infrastructure (for example road use). These effects also require careful planning due to land resource constraints.

The importance of identifying the impact of transportation demand and economic activity on infrastructure and the environment is clear. However, gathering the data needed for this is not straightforward. Historically, planners have relied on data gathered from freight activity surveys or lading bills. These methodologies are well-known and have always offered good results. Nonetheless, the cost and tediousness of these data gathering processes hinder their ability to offer quick turnaround times for transport policy planning.

The methodology proposed in this paper addresses the issues of cost and data gathering speed. A multivariate model approach was tested in China, India and Saudi Arabia. The model tests the possibility of using nighttime lights (NTL) data as an independent variable to determine freight transportation activity.

This approach is based on assessing the potential for FTA estimation using different NTL technologies. The NTL data is from the United States Air Force Defense Meteorological Satellite Program's Operational Linescan System (DMSP-OLS) that dates back to 1994 and the Suomi National Polar-orbiting Partnership's Visible Infrared Imaging Radiometer Suite (NPP-VIIRS), which dates back to 2013.

Estimations for the three countries are made in order to test the robustness of the approach, independently of location and the period for which NTL data is available.

\section{Data on freight transport activity}

For the purpose of this exercise, FTA in metric tonnes is designated as a dependent variable. FTA is composed of road, rail, air, maritime and inland waterway transport. This study only considers internal transportation activity for China, India and Saudi Arabia. Annex 2 gives the tables of values used for the respective countries' FTAs.

The study looks at mainland China, which includes 27 provinces and four municipalities (Beijing, Shanghai, Tianjin and Chongqing), between 2012-2015.

India's total freight activity is based on the statistics in the RITES dataset for 2007/2008. The data presented are consistent with all origin and destination tonnes for internal freight movement in India on all modes. 
The data used for Saudi Arabia on the tonnage of freight transported internally was calculated using data from the General Authority of Statistics (GaStat) of Saudi Arabia from 2012 to 2017. The tonnage by region was estimated from regional production data, export and import statistics by sector (internal legs). The sectors accounted for are mining and quarrying (excluding oil production for export and internal consumption), refining, manufacturing, livestock and main agricultural products. The FTA data are separated into the 13 provinces of Saudi Arabia and represent internal road and rail transportation.

\section{Data on nighttime lights}

All the composite sets for NTL are from the DMSP Operational Linescan System and the NPPVIIRS data recently released by NOAA. VIIRS images have a higher spatial resolution and wider radiometric detection range compared to the DMSPOLS NTL data. However, VIIRS data are only available starting from 2012.

The version 4 DMSP-OLS stable lights yearly image composites for 2007 (only in the case of India), 2012, and 2013 are collected from the official NOAA website of the National Centers for Environmental Information. The annual image composites were produced using the stable lights images from which the background noise and ephemeral events have been discarded or replaced. The analysis was done with data from after 2012, using VIIRS satellite images with cloud-free coverage. Monthly averages were used for VIIRS for 2012, 2013, and 2014 because at the time of conducting this study the annual composite for these three years had not yet been released. However, for other years we used the annual composites released by NOAA.

Figure 1. Nighttime lights 2012 - flat map.

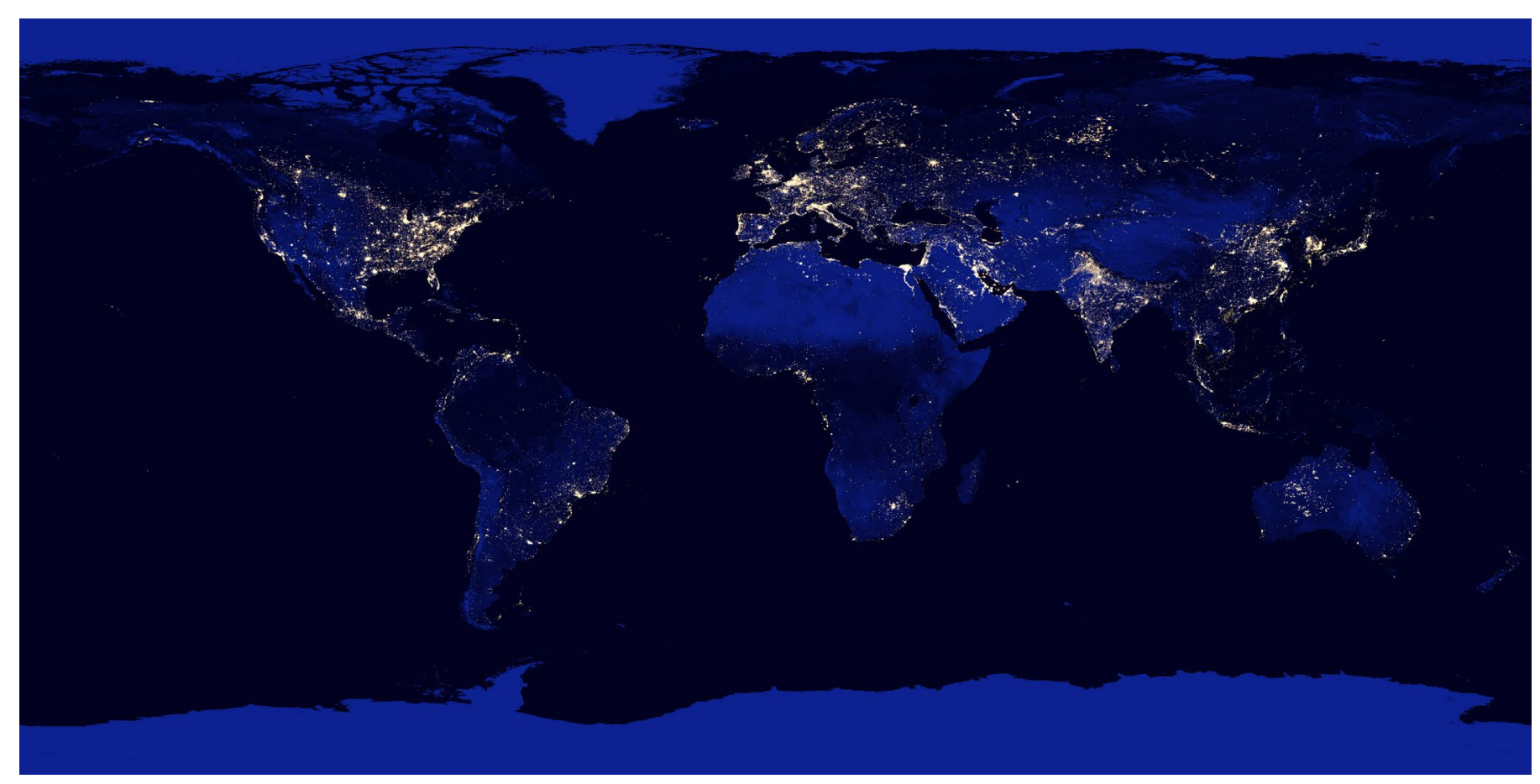

Source: NASA Earth Observatory. 
Table 1. Independent variables for the FTA model.

\begin{tabular}{l|l|l|l} 
Independent variables & Unit & Source & Notes \\
$\begin{array}{l}\text { DMSP nighttime lights } \\
\text { time series }\end{array}$ & nanoWatts/cm²/sr & $\begin{array}{l}\text { National Ocean and } \\
\text { Atmospheric Administration } \\
\text { (NOAA) DMSP-OLS }\end{array}$ & $\begin{array}{l}\text { The images used are cloud-free } \\
\text { composites made using all the available } \\
\text { archived DMSP-OLS smooth resolution } \\
\text { data for calendar years. }\end{array}$ \\
\hline $\begin{array}{l}\text { VIIRS nighttime lights time } \\
\text { series }\end{array}$ & nanoWatts/cm2/sr & $\begin{array}{l}\text { National Ocean and } \\
\text { Atmospheric Administration } \\
\text { (NOAA) VIIRS }\end{array}$ & $\begin{array}{l}\text { The images used are cloud-free average } \\
\text { radiance values that have undergone an } \\
\text { outlier removal process to filter out fires } \\
\text { and other ephemeral lights. }\end{array}$ \\
\hline Population & Thousands of people & Chinese Statistical Yearbook & $\begin{array}{l}\text { This variable was only used for the } \\
\text { Chinese estimation. An explanation } \\
\text { will be addressed in the following } \\
\text { paragraphs . }\end{array}$
\end{tabular}

Source: Authors' compilation.

A monthly average composite was used for years where no yearly composite was available. It is important to note that the yearly composite is an average of 365 daily observations. Thus, the range in values of radiance for daily and monthly composites are no different from the range of values in the yearly composite. However, daily and monthly composites can suffer heavily from air pollution coverage. They can also be influenced by seasonality. Wherever yearly composites were missing, the monthly composite for April was used because the temperature in April is quite mild, and there are few holidays or celebrations that month, in the countries used in this study.

The resolution and accuracy of NPP-VIIRS over DMSP-OLS is unquestionable. However, DMSPOLS images were publicly available from 1994 to 2013, whereas NPP-VIIRS images have only been available from 2013.

Since DMSP-OLS and VIIRS do not have the same resolution, Alexei Abrahams has proposed an algorithm for de-blurring DMSP-OLS and rendering it so that it is visually comparable with VIIRS for analytical purposes. Because only the sum of lights was taken into consideration as a variable for specific years, the difference between DMSP and VIIRS did not impact the analysis.

The following section discusses the elasticity tests conducted between NTL and FTA and showcases the stability of the technologies over the years.

\section{Freight transport activity (FTA) estimation using nighttime lights (NTL)}

Calculating the FTA uses the approach established by Shi et al. (2014) and Tian (2014), where a relationship is stated between the sum of the radiance inside a defined administrative boundary and the total freight in the following functional form of total freight transport activity (FTA), as a linear function of the observed nighttime lights (NTL):

$$
\ln (F T A)=\beta * \ln (N T L)+c
$$


Where $\beta$ is the linear coefficient and $c$ is the intercept.

We increased the number of observations for the three countries for all the regressions by creating a panel dataset with states/provinces and years.

The first run of the regression analysis shows statistically good results for India and Saudi Arabia (see Tables 2 and 3). The Chinese results (Table 4a) are on the lower bound of an acceptable result for a regression

The April 2014 composite NTL image for China shows a big cloud over Shanghai. The 2013 image for China also shows cloud coverage over Shanghai, though it is less noticeable compared with 2014 because it is a yearly composite. Hence, Shanghai

Table 2. Regression results for India at the state level.

Summary output

Regression statistics

\begin{tabular}{|c|c|c|c|c|c|c|}
\hline \multicolumn{2}{|l|}{ Multiple R } & \multicolumn{2}{|l|}{0.940684} & & & \\
\hline \multicolumn{2}{|l|}{ R square } & \multicolumn{2}{|l|}{0.884887} & & & \\
\hline \multicolumn{2}{|c|}{ Adjusted R square } & \multicolumn{2}{|l|}{0.881174} & & & \\
\hline \multicolumn{2}{|c|}{ Standard error } & \multicolumn{2}{|l|}{0.673481} & & & \\
\hline \multirow[t]{2}{*}{ Observations } & & \multicolumn{2}{|l|}{33} & & & \\
\hline & Coefficients & Standard error & t Stat & P-value & Lower 95\% & Upper 95\% \\
\hline Intercept & 6.493354 & 0.73228 & 8.867316 & $5.21 \mathrm{E}-10$ & 4.99986 & 7.986848 \\
\hline NTL & 0.944646 & 0.061194 & 15.43699 & $4.22 E-16$ & 0.81984 & 1.069451 \\
\hline
\end{tabular}

Source: Authors' calculations.

Table 3. Regression results for Saudi Arabia at the regional level.

Summary output

Regression statistics

\begin{tabular}{|c|c|c|c|c|c|c|}
\hline \multicolumn{2}{|l|}{ Multiple R } & \multicolumn{2}{|l|}{0.862513} & & & \\
\hline \multicolumn{2}{|l|}{ R square } & \multicolumn{2}{|l|}{0.743928} & & & \\
\hline \multicolumn{2}{|c|}{ Adjusted R Square } & \multicolumn{2}{|l|}{0.739864} & & & \\
\hline \multicolumn{2}{|c|}{ Standard error } & \multicolumn{2}{|l|}{0.314581} & & & \\
\hline \multirow[t]{2}{*}{ Observations } & & \multicolumn{2}{|l|}{65} & & & \\
\hline & Coefficients & Standard error & t Stat & P-value & Lower 95\% & Upper 95\% \\
\hline Intercept & -5.57247 & 0.735111 & -7.58045 & $1.93 E-10$ & -7.04147 & -4.10347 \\
\hline NTL & 1.466305 & 0.108385 & 13.52866 & 2.67E-20 & 1.249714 & 1.682895 \\
\hline
\end{tabular}

Source: Authors' calculations. 
Table 4a. Regression results for China at the province level with NTL as an explanatory variable.

Summary output

Regression statistics

\begin{tabular}{|c|c|c|c|c|c|c|}
\hline \multicolumn{2}{|c|}{ Multiple R } & \multicolumn{2}{|l|}{0.759684} & & & \\
\hline \multicolumn{2}{|l|}{$\mathrm{R}$ square } & \multicolumn{2}{|l|}{0.577119} & & & \\
\hline \multicolumn{2}{|c|}{ Adjusted R Square } & \multicolumn{2}{|l|}{0.572472} & & & \\
\hline \multicolumn{2}{|c|}{ Standard error } & \multicolumn{2}{|l|}{0.710154} & & & \\
\hline \multicolumn{2}{|c|}{ Observations } & \multicolumn{2}{|l|}{93} & \multirow[b]{2}{*}{ P-value } & \multirow[b]{2}{*}{ Lower 95\% } & \multirow[b]{2}{*}{ Upper $95 \%$} \\
\hline & Coefficients & Standard error & t Stat & & & \\
\hline Intercept & -0.64785 & 1.084425 & -0.59741 & 0.551716 & -2.80193 & 1.506228 \\
\hline NTL & 0.899837 & 0.080746 & 11.14409 & 1.07E-18 & 0.739446 & 1.060229 \\
\hline
\end{tabular}

Source: Authors' calculations.

presents itself as an outlier with relatively lower than normal NTL in 2014 when compared with other Chinese provinces and radiance results for other years. This is not out of the ordinary, the literature on meteorology is extensive. For example, the issue of the North China Plain and Eastern China being prone to haze pollution that affects satellite observations is discussed by Chameides et al. (1999), Ramanathan et al. (2007) and in Tao et al. (2012).

To solve this drawback of the analysis, only yearly composites of nightlights were used for China (2012, 2013 and 2015), which reduced the overall effect of its pollution haze. The monthly composites for China had high variability in light intensity values from one month to another, as they are dependent on $\mathbf{3 0}$ daily observations. The analysis using monthly images was not changed for Saudi Arabia and India as the same composites did not present this variability in NTL intensity.

Moreover, two approaches were taken to assess the appropriate statistical model for FTA estimation in
China. The first approach was to eliminate provinces covered by the pollution haze in the north and east of the country. The second approach was to add a socioeconomic variable that would not be affected by pollution haze. In this case, the census population data for each year was included to see whether there would be an increase in the quality of the regression model.

Each of these two approaches increased the regression results. In the case of the first approach, which required eliminating the provinces from the observations, the results improved. However, the possibility of using the first approach was rejected as there was an important drawback, the elimination of economically significant regions (i.e., Shanghai). The sheer economic size of the provinces that were eliminated from the observations would affect the validity of the approach.

The second approach, which integrated an extra socio-economic explanatory variable, yielded positive results, as shown in Table 4b. The statistical results of the regression are comparable to those 
of Saudi Arabia and India when integrating the populations of provinces as another variable.

Tables $4 \mathrm{a}$ and $4 \mathrm{~b}$ show the differences in the statistical model for China before and after integrating population as an explanatory variable. Both results are useful. However, it would be up to the modeler to choose if the integration of a second explanatory variable is warranted in order to make up for the loss of visibility due to pollution coverage.

It is important to note that some countries and/or time periods can suffer from haze pollution and or cloud coverage issues that might render certain images unusable, such as is the case in China. This presents problems when carrying out a time series analysis. Although the Chinese haze pollution drawback was addressed, punctual effects can be worked around by integrating other variables or by looking for monthly composites unaffected by haze pollution (taking into account the effects of seasonality). The consideration of time-related issues leads to a further question regarding the stability of the correlation of NTL with time, taking into account the change in image acquisition technology (DMSP-VIIRS) in 2012. The answer to this particular question is crucial as it would validate or invalidate the use of pre-2012 images for time-series analysis and/or forecasting.

We ran tests using cross-sectional data regressions for each year for which data for both Saudi Arabia and China were available. This allowed us to test the validity of integrating datasets with different image acquisition technologies (DMSP versus VIIRS) across different years.

The units reported by NASA for both DMSP and VIIRS are nanowatt per square centimeter steradian (nanoWatts $/ \mathrm{cm}^{2} / \mathrm{sr}$ ). However, the fact that the resolution between DMSP and VIIRS is different raises the question: how valid is it to mix the radiance observations for both technologies without using some corrective algorithm?

Table 4b. Regression results for China at the province level with NTL and population as explanatory variables.

Summary output

\section{Regression statistics}

\begin{tabular}{|c|c|c|c|c|c|c|}
\hline \multicolumn{2}{|l|}{ Multiple R } & \multicolumn{2}{|l|}{0.874128} & & & \\
\hline \multicolumn{2}{|l|}{ R Square } & \multicolumn{2}{|l|}{0.764099} & & & \\
\hline \multicolumn{2}{|c|}{ Adjusted R Square } & \multicolumn{2}{|l|}{0.758857} & & & \\
\hline \multicolumn{2}{|c|}{ Standard Error } & \multicolumn{2}{|l|}{0.533344} & & & \\
\hline \multicolumn{2}{|c|}{ Observations } & \multicolumn{2}{|l|}{93} & \multirow[b]{2}{*}{ P-value } & \multirow[b]{2}{*}{ Lower 95\% } & \multirow[b]{2}{*}{ Upper 95\% } \\
\hline & Coefficients & Standard error & t Stat & & & \\
\hline Intercept & -3.45068 & 0.879445 & -3.9237 & 0.00017 & -5.19785 & -1.70351 \\
\hline NTL & 0.868035 & 0.060759 & 14.28654 & 7.23E-25 & 0.747326 & 0.988743 \\
\hline POP & 0.288085 & 0.034109 & 8.446063 & $4.88 \mathrm{E}-13$ & 0.220322 & 0.355848 \\
\hline
\end{tabular}

Source: Authors' calculations. 
Given that both DMSP and VIIRS measure radiance in the same way, and that the difference between them is the resolution, mixing DMSP and VIIRS images should not be a problem. Indeed, the difference in measurement between DMSP and VIIRS should be a constant factor and would, therefore, not have an impact on the regression results.

Tables 5 and 6, depict the relationship between NTL and FTA as stable in time. The differences in NTL/ FTA coefficients between DMSP and VIIRS are negligible.

This analysis, used to verify that DMSP and VIIRS values can be used for FTA estimation over a certain period, has resulted in an important observation: the changing FTA/NTL elasticity in resource-intensive economies.
The NTL coefficients in Table 6 show that the relationship between NTL and FTA across various years for Saudi Arabia is unstable, particularly for 2016 and 2017. The values range between a coefficient of 1.2 in 2012 and 1.9 in 2017, the most important increases being observed in 2016 and 2017.

It is important to note that this variability is not due to a difference between the coefficients estimated for the intensity of NTL measured with DMSP technology (2012 and 2013) and VIIRS technology (2014 -2017) but is due to the structure of Saudi Arabia's economy, not to changes in satellite technology. Indeed, during 2016 and 2017 the production activity measured in tonnes (reported in the statistics) falls as luminosity rises. An explanation for this might be found in the change in oil extraction that occurred in the same period

Table 5. Summary of coefficients for China.

$\begin{array}{lll}\text { Coefficients + stats } & 2012 \text { DMSP } & 2013 \text { DMSP }\end{array}$

\begin{tabular}{llll}
\hline Intercept & -3.772 & 0.002 & -2.318 \\
\hline NTL & 1.114 & 1.006 & 1.067 \\
\hline Multiple R & 0.852 & 0.997 & 0.801 \\
\hline R square & 0.726 & 0.993 & 0.641 \\
\hline P-value & $1.22 \mathrm{E}-09$ & $2.97 \mathrm{E}-33$ & $6.33 \mathrm{E}-08$ \\
\hline
\end{tabular}

Source: Authors' calculations.

Table 6. Summary of coefficients for China.

\begin{tabular}{lllllll}
$\begin{array}{l}\text { Coefficients }+ \\
\text { stats }\end{array}$ & $\mathbf{2 0 1 2}$ DMSP & $\mathbf{2 0 1 3}$ VIIRS & 2014 VIIRS & 2015 VIIRS & 2016 VIIRS & 2017 VIIRS \\
\hline Intercept & -2.704 & -4.872 & -5.191 & -5.235 & -6.822 & -9.019 \\
\hline NTL & 1.272 & 1.383 & 1.431 & 1.422 & 1.646 & 1.925 \\
\hline Multiple R & 0.781 & 0.887 & 0.902 & 0.887 & 0.916 & 0.946 \\
\hline R square & 0.610 & 0.786 & 0.814 & 0.786 & 0.839 & 0.896 \\
\hline P-value & $1.63 \mathrm{E}-03$ & $5.37 \mathrm{E}-05$ & $2.46 \mathrm{E}-05$ & $1.18 \mathrm{E}-04$ & $1.10 \mathrm{E}-05$ & $9.88 \mathrm{E}-07$ \\
\hline
\end{tabular}

Source: Authors' calculations. 
as the study. In other words, it is not surprising that there was an increase in the NTL/FTA coefficient in 2016 and 2017 when oil prices were low, which implies an increase in extraction levels, with a decrease in the production levels of other industries.

The results in Table 6 show that NTL estimation of FTA is not only highly dependent on atmospheric pollution conditions, it is also highly sensitive to changes in a country's economic structure and the energy use in transport-intensive industries. This suggests that the methodology for FTA estimation using NTL should be coupled with a control method that takes into account meteorological conditions during the period of study as well as general economic trends and characteristics of the regions and countries being studied. 


\section{Conclusion}

he KAPSARC Transport Analysis

Framework (KTAF) estimates transport activity from freely available global data sources, satellite images and nighttime lights. It is a tool for estimating freight transport activity that can be used in models to measure the impact of an accelerated transport policy planning approach.

By focusing on China, India and Saudi Arabia, we established that using NTL for FTA estimation is a valid approach for different countries, regardless of their economic, social and political composition. We encountered a number of hurdles in the use of NTL in FTA estimation such as the lack of NTL data due to pollution cloud coverage or gaps in the yearly composites, differences between DMSP and VIIRS technologies for different years, or the sensitivity of transport activities to economic structures. The paper discussed all of these hurdles and the methods used to overcome them.

Additionally, the experience that informed this paper resulted in the development of a guide detailing the step-by-step process of how to use NTL to estimate FTA (Annex 1). Alhassan (2019) developed the code that automatically extracts light values for any country for Matlab and is freely available on Matlab's repository.

In addition, the methodology detailed in this paper builds on current state of the art transportation modeling in three key areas:

Studying the relationship between NTL and FTA opens the door to estimate full transportation datasets for countries where only a few observation points exist or where data is unavailable.
Estimations that can be as periodic as the release of daily NTL data can be carried out. In addition, these estimations can be realized globally with an open source methodology and dataset.

Finally, this paper establishes the foundation for future work on how to use this approach in transport flow estimation. It has demonstrated the estimation of overall transportation demand. The next step is for researchers to use this as an input into transport flow estimation.

Continued research on zoning and clustering algorithms that are adapted to this estimation methodology is key to developing this approach using NTL. Although the results for estimation using administrative regions are good, initial tests show that the estimation procedure could benefit from continued improvement. These would be statistical and resource benefits.

Although the relationship between FTA and NTL is stable on a year-by-year basis, the economic structure of countries is an important factor in the stability of FTA and NTL coefficients in the mid to long term. Further exploration of the nature of this relationship is required in future research efforts. Tables 5 and 6 indicate that the coefficients for China and Saudi Arabia are almost identical year after year in the short term and in the absence of an economic crisis.

Moreover, the nature of the coefficients differs between countries. The elasticity between NTL and FTA is different in India, China and in Saudi Arabia (Tables 2, 3 and 4a). This confirms that the relationship between economic activity and transportation is different from country to 
country. The difference in elasticities is not new; it is directly linked to the structure of a country's economic, production and transportation systems. FTA estimation through NTL offers an interesting approach in producing a direct measure of the relationship between economic and production structures on transportation activities. This can then be used to forecast the evolution of FTA in accordance with economic developments in a specific country. This indicator is particularly relevant for freight transportation, as the effects of policy measures are highly dependent on economic structure and vice versa. Although this methodology paper does not explore this relationship, it does open the door to the possibility of future research focused on the insights that might be extracted from the relationship between economic structure and energy demand in transportation. 


\section{References}

Abrahams, Alexei. 2015. "Improving the Granularity of Nighttime Lights Satellite Imagery." The World Bank, blog entry, May 25. Accessed Aug. 1, 2018. blogs. worldbank.org/impactevaluations/improving-granularitynighttime-lights-satellite-imagery-guest-post-alexeiabrahams

Alhassan, Reema. 2019. "Calculate the Sum of the nightlights data from TIFF images." MATLAB Central File Exchange. Retrieved Feb. 17, 2019. https://www. mathworks.com/matlabcentral/fileexchange/70035calculate-the-sum-of-the-nightlights-data-from-tiffimages

Assuncao, Renato Martins, Neves, Marcos Correa, Camara, Gilberto and Freitas, Domingos Antonia Da Costa. 2006. "Efficient regionalization techniques for socio-economic geographical units using minimum spanning trees." International Journal of Geographical Information Science 20 (7): 797-81. Doi: https://doi. org/10.1080/13658810600665111

Chen, Xi and William, Nordhaus. 2011. "Using Luminosity Data as a Proxy for Economic Statistics." Proceedings of the National Academy of Sciences 108 (21): 8589-8594. Doi: https://doi.org/10.1073/ pnas.1017031108

China City Statistical Yearbook 2014. 2015. "Freight Ton-kilometers by Prefectures (2013)." China Statistics Press. http://tongji.cnki.net/kns55/navi/YearBook. aspx?id=N2016030128\&floor=1\#\%23\%23

China City Statistical Yearbook 2015. 2016. "Freight Ton-kilometers by Region (2014)." China Statistics Press. http://tongji.cnki.net/kns55/navi/YearBook. aspx ?id=N2016030128\&floor=1\#\%23\%23

China Statistical Year Book 2014. 2015. "Table 18-15 Freight Ton-kilometers by Region (2013)." China Statistics Press. http://www.stats.gov.cn/tjsj/ndsj/2014/ zk/html/Z1815E.xls

China Statistical Year Book 2015. 2016. "Table 18-15 Freight Ton-kilometers by Region (2014)." China Statistics Press. http://www.stats.gov.cn/tjsj/ndsj/2015/ html/EN1815.jpg
Doll, Christopher N.H., Jan-Peter Muller, and Jeremy G. Morley. 2006. "Mapping regional economic activity from night-time light satellite imagery." Ecological Economics 57 (1): 75-92. Doi: https://doi.org/10.1016/j. ecolecon.2005.03.007

Jing, Xin, Xi Shao, Changyong Cao, Xiaodong Fu, Lei Yan. 2016. "Comparison between the Suomi-NPP Day-Night Band and DMSP-OLS for Correlating SocioEconomic Variables at the Provincial Level in China." Remote Sensing 8 (1): 17. Doi: https://doi.org/10.3390/ rs8010017

Elvidge, Christopher, Kimberly Baugh, K. et al. 2013. "Why VIIRS data are superior to DMSP for mapping nighttime lights" Proceedings of the AsiaPacific Advanced Network 35: 62-69. Doi: https://doi. org/10.7125/apan.35.7

Lowe, Matt. 2014. "Night lights and ArcGIS: A brief guide." Technical report, MIT. http://economics.mit.edu/ files/8945

National Centers of Environmental Information, National Oceanic and Atmospheric Administration NOAA, Earth Observatory Group. 2013. "Version 4 DMSP-OLS Calendar Years Nighttime Stable Lights, Time Series (30 arc second grids, spanning -180 to 180 degrees longitude and -65 to 75 degrees latitude)." http://ngdc. noaa.gov/eog/dmsp/downloadV4composites.html Geotiff available at: http://ngdc.noaa.gov/eog/data/web_data/ v4composites/F182013.v4.tar

NASA Goddard Space Flight Center, Ocean Ecology Laboratory, Ocean Biology Processing Group. 2014. "VIIRS-NPP Tile 3 Tile 3 (75N/060E) Asia Region Monthly Composites Average Radiance" http://ngdc. noaa.gov/eog/viirs/download_monthly.html Tile Geotiff avaliable at: http://mapserver.ngdc.noaa. gov/viirs_data/viirs_composite/v10//201401/vcmcfg/ SVDNB_npp_20140101-20140131_75N060E_vcmcfg_ v10_c201506171538.tgz

Pinkovskiy, Maxim, and Xavier Sala-i-Martin. 2016. "Lights, Camera... Income! Illuminating the National Accounts-Household Surveys Debate." The Quarterly Journal of Economics 131 (2): 579-631. Doi: https://doi. org/10.1093/qje/qjw003 
RITES Ltd (2014). "Base Year Freight Traffic Flows: Railways, Highways, Airways and Coastal Shipping" Planning Commission Study: Total Transport System, Study on Traffic Flows and Modal Costs (Highways, Railways, Airways and Coastal Shipping), Chapter 3. http://planningcommission.gov.in/reports/genrep/index. php?repts=rites.html

Rybnikova Natalya, Boris Portnov. 2015. "Using light at night satellite data for identifying clusters of economic activities in Europe." The International Archives of the Photogrammetry, Remote Sensing and Spatial Information Sciences XL-7/W3. Doi: https://doi. org/10.5194/isprsarchives-xl-7-w3-1403-2015

Shi, Kaifang, Bailang Yu, Yixiu Huang, Yingjie Hu, Bing Yin, Zuoqi Chen, Liujia Chen, Jianping Wu. 2014. "Evaluating the Ability of NPP-VIIRS Nighttime Light Data to Estimate the Gross Domestic Product and the Electric Power Consumption of China at Multiple Scales: A Comparison with DMSP-OLS Data." Remote Sensing 6 (2): 1705-1724. Doi: https://doi.org/10.3390/rs6021705
Kaifang Shi, Bailang Yu, Yingjie Hu, Chang Huang, Yun Chen, Yixiu Huang, Zuoqi Chen \& Jianping Wu. 2015. "Modeling and mapping total freight traffic in China using NPP-VIIRS nighttime light composite data." GIScience \& Remote Sensing 52(3): 274-289. Doi: https://doi.org/10.1080/15481603.2015.1022420

Jingru Tian, Naizhuo Zhao, Eric L. Samson, Shuliang Wang. 2013. "Brightness of Nighttime Lights as a Proxy for Freight Traffic: A Case Study of China". IEEE Journal of Selected Topics in Applied Earth Observations and Remote Sensing 7 (1): 206-212. Doi: https://doi. org/10.1109/jstars.2013.2258892 
Notes 


\section{Notes}


Notes 


\section{Annex 1: Calculating the Sum of Nighttime Lights in ArcGIS}

1. Import nighttime light file.

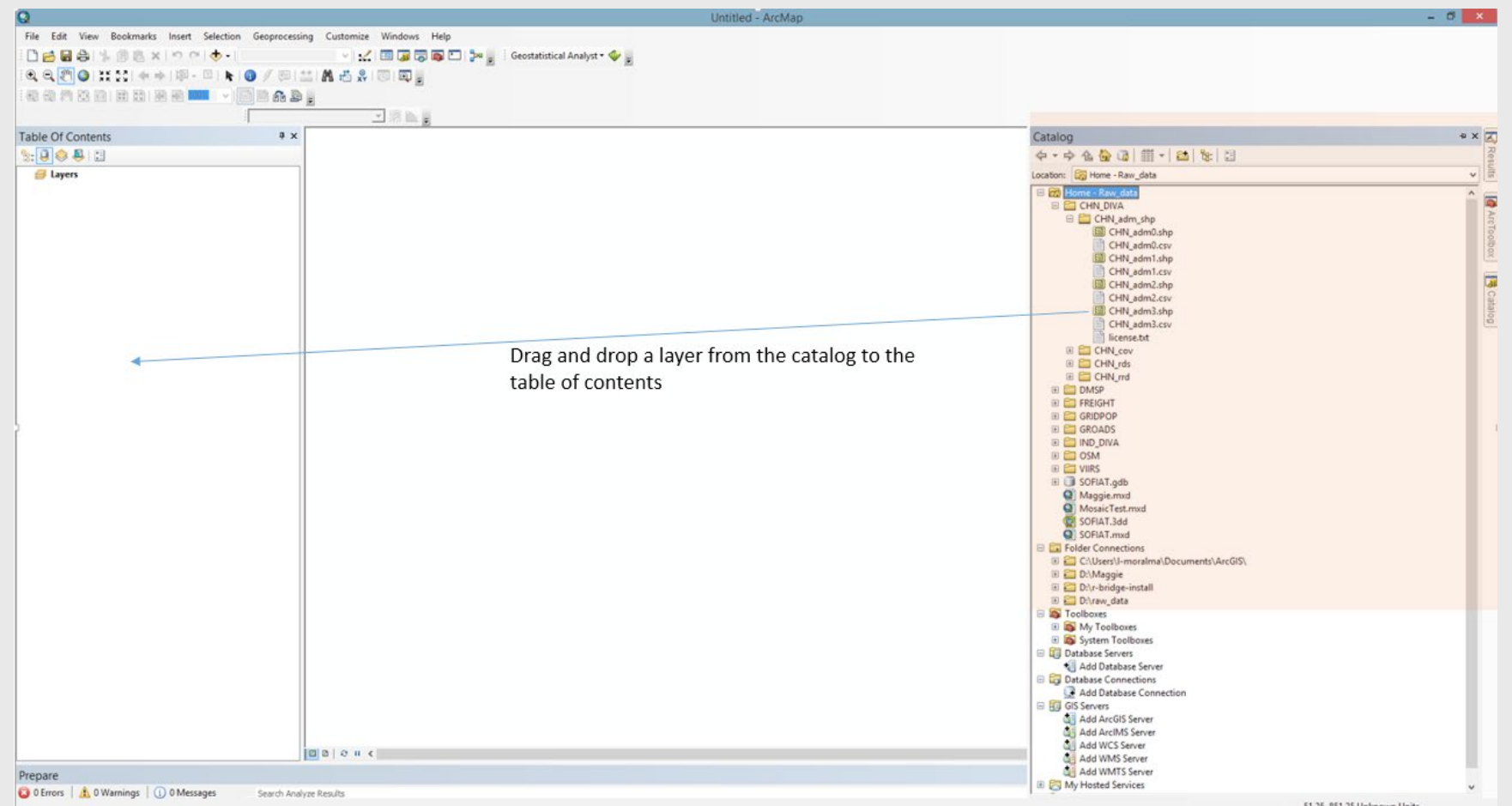

2. If the nighttime image is black, adjust visual minimum/maximum properties of the image (this does not affect values contained in the image).

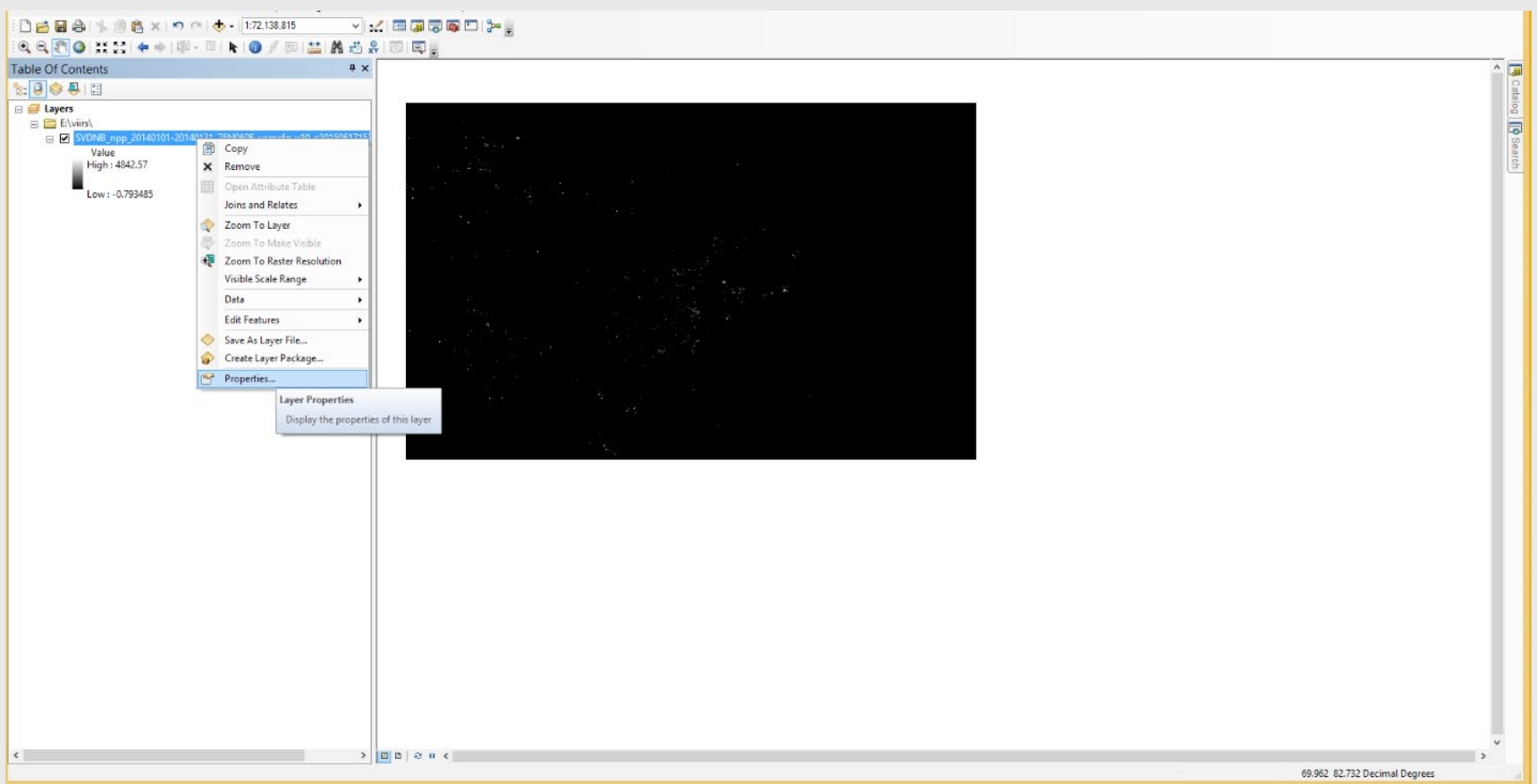


3. Select Data Management Tools.tbx/Raster/Raster Formatting/Clip Toolbox.

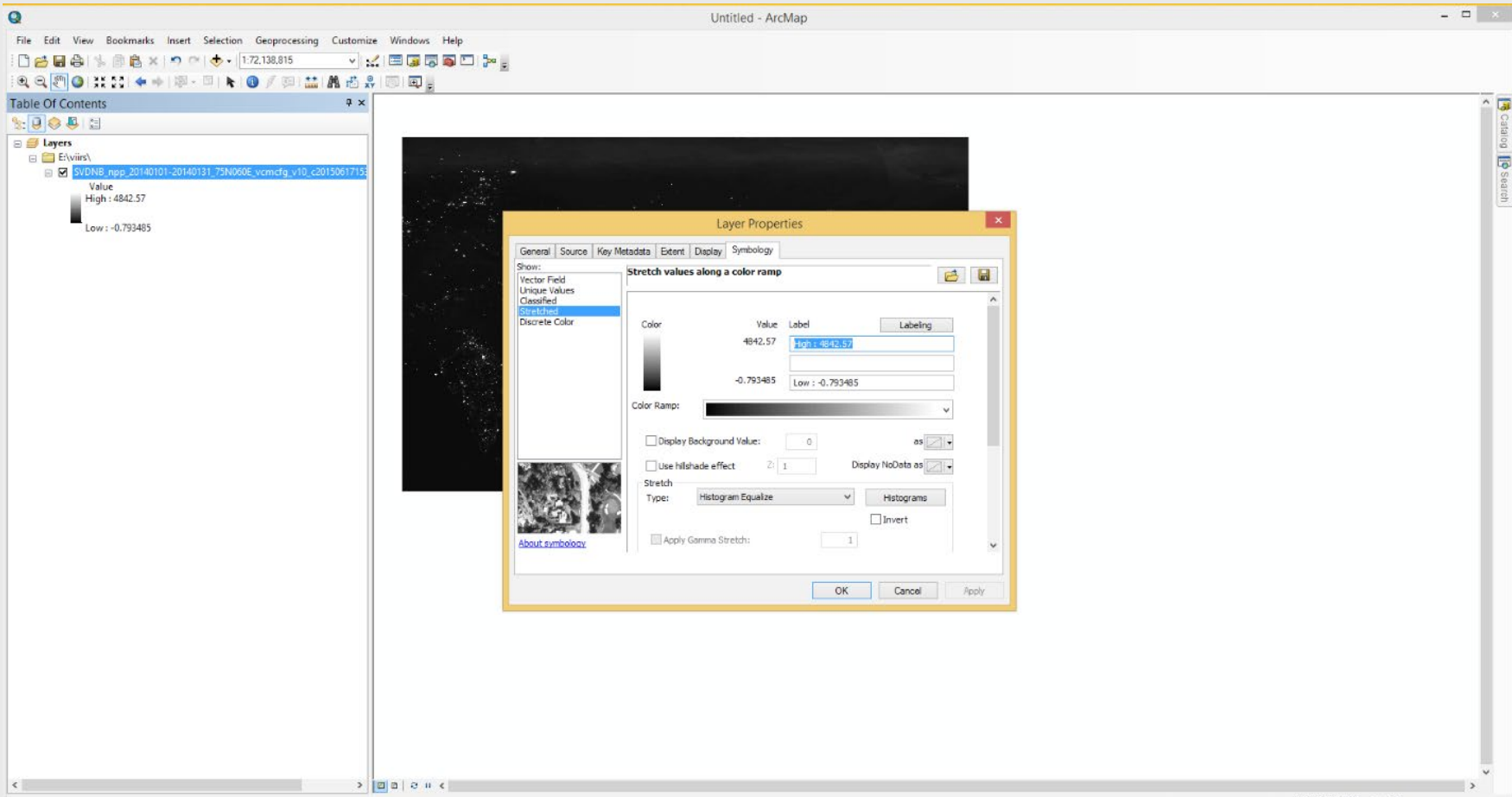

4. Clipping Menu. Use clipping geometry and maintain extent.

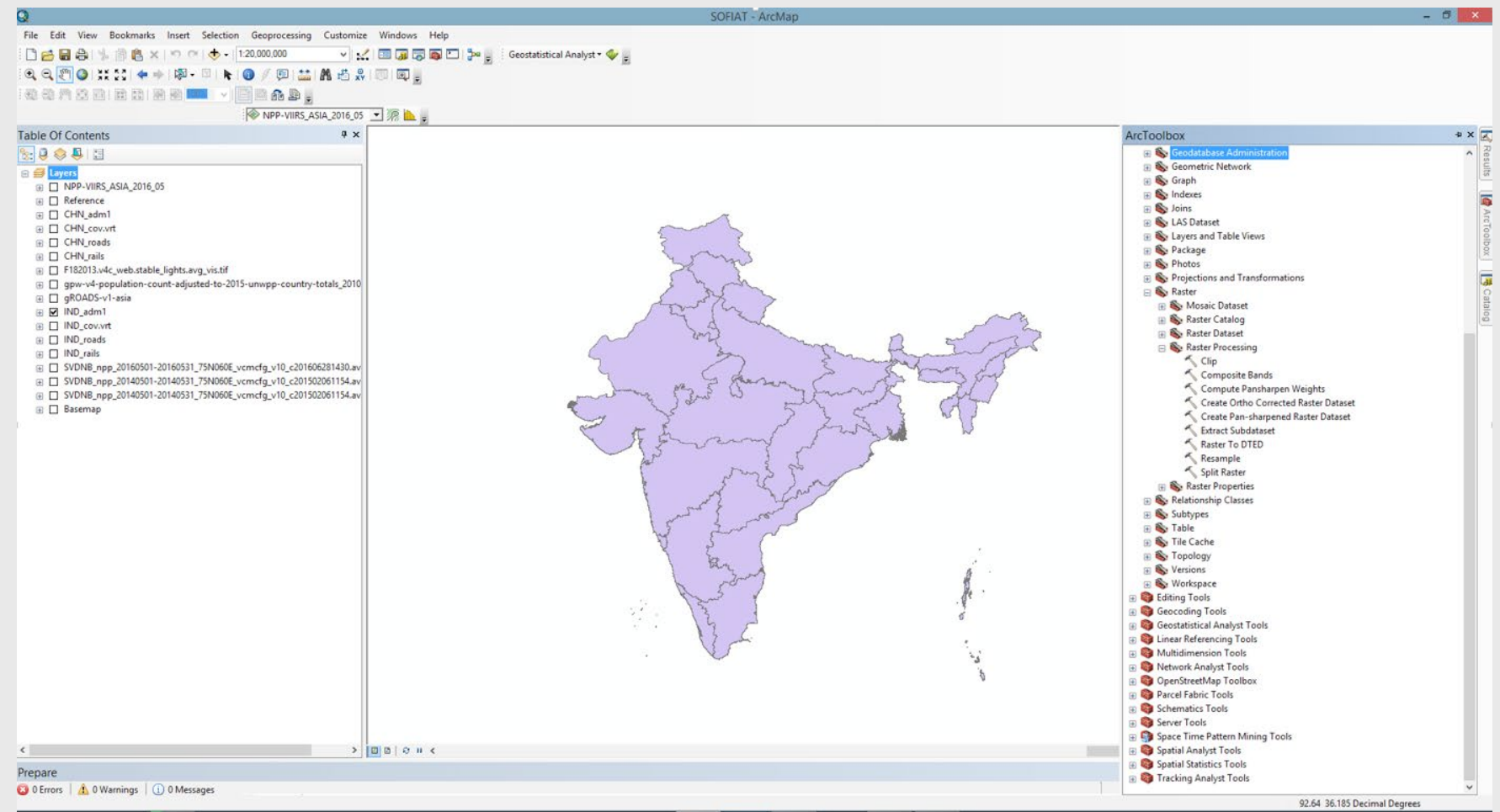




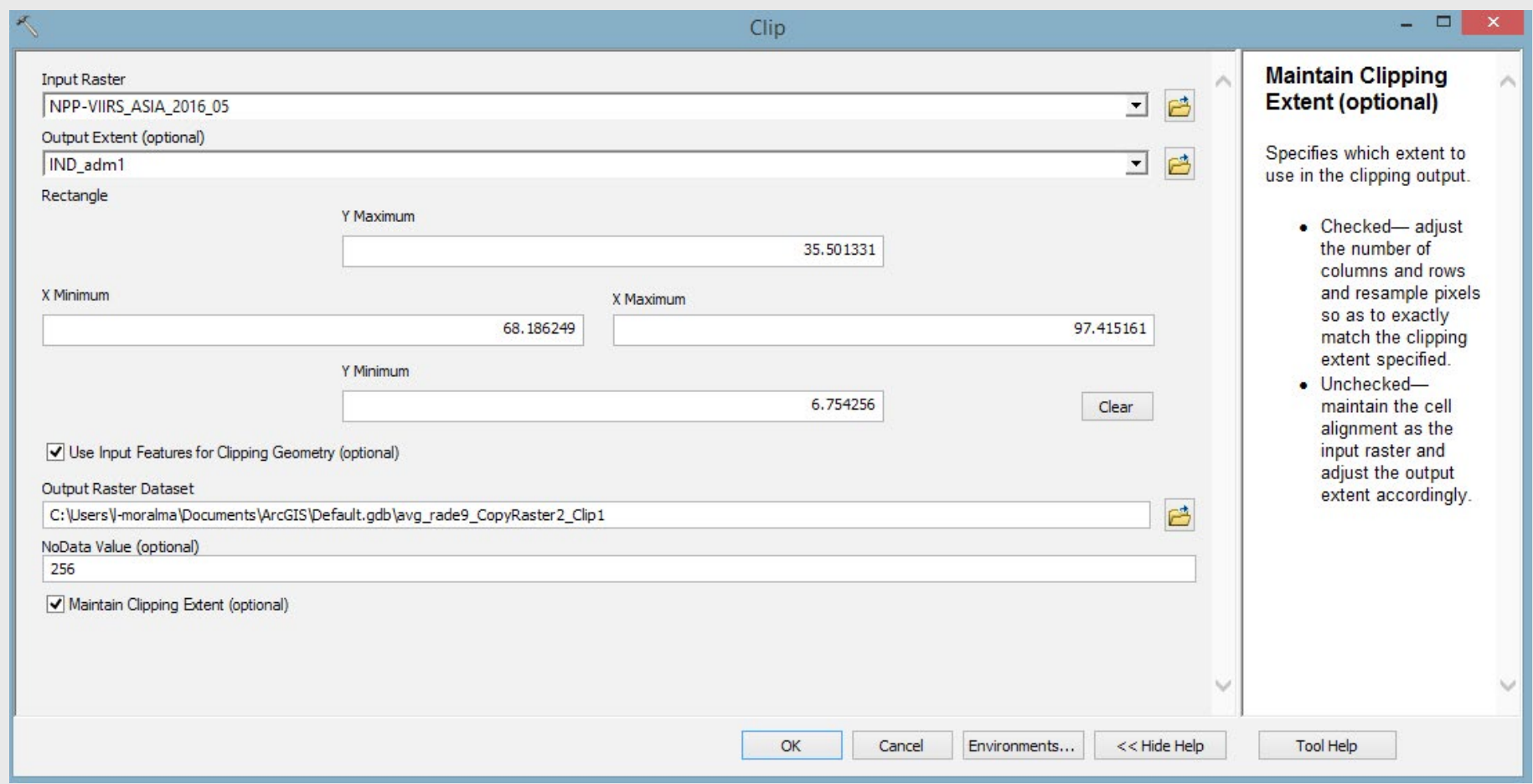

Result of step 4.

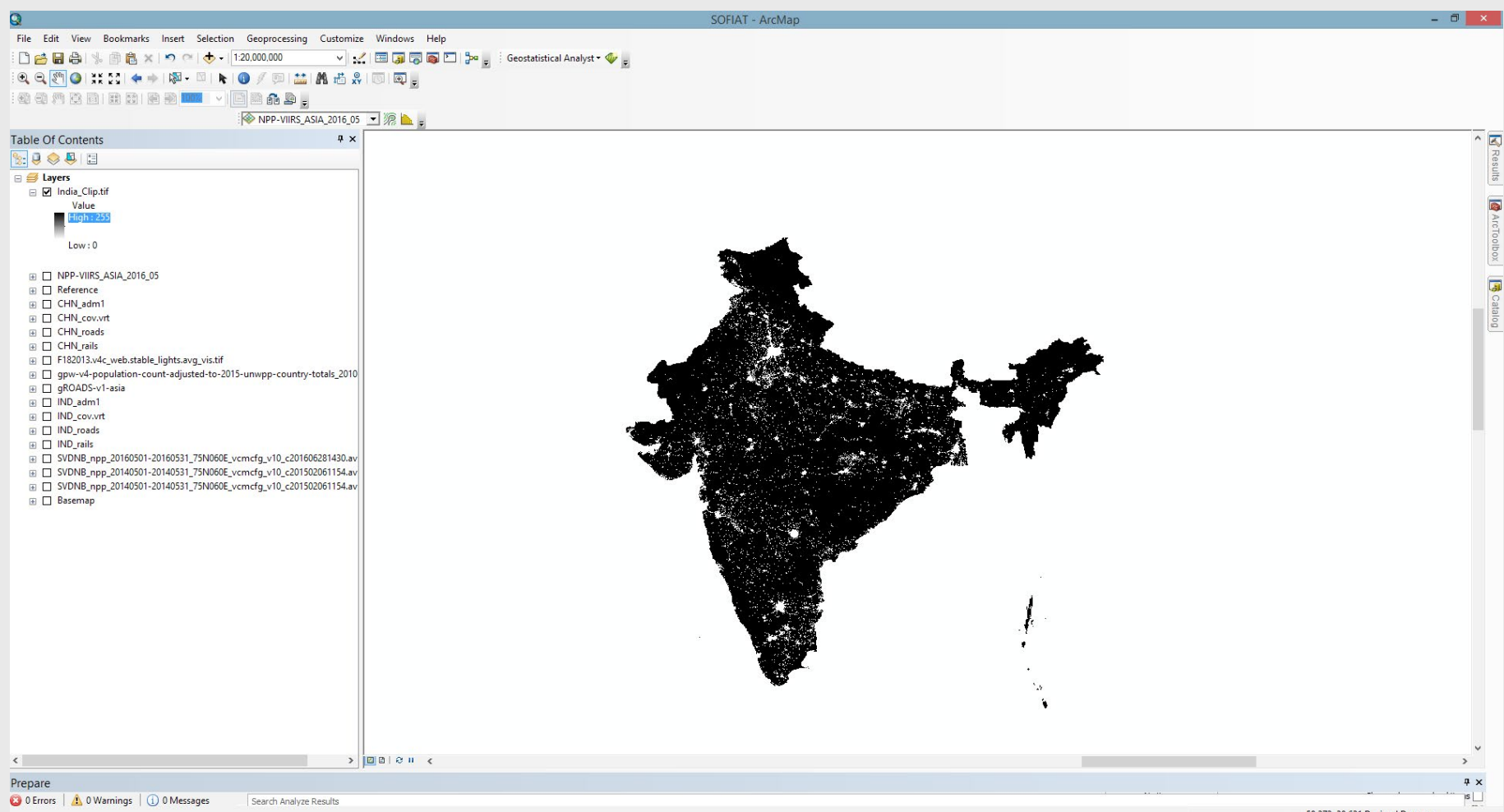

By using the last clipped image, we want to extract the sum or light per province and, for that task, we can use the spatial analyst tools / Zonal Statistics as a Table. 
5. Select Spatial Analyst Tools/Zonal/Zonal Statistics as Table Toolbox.

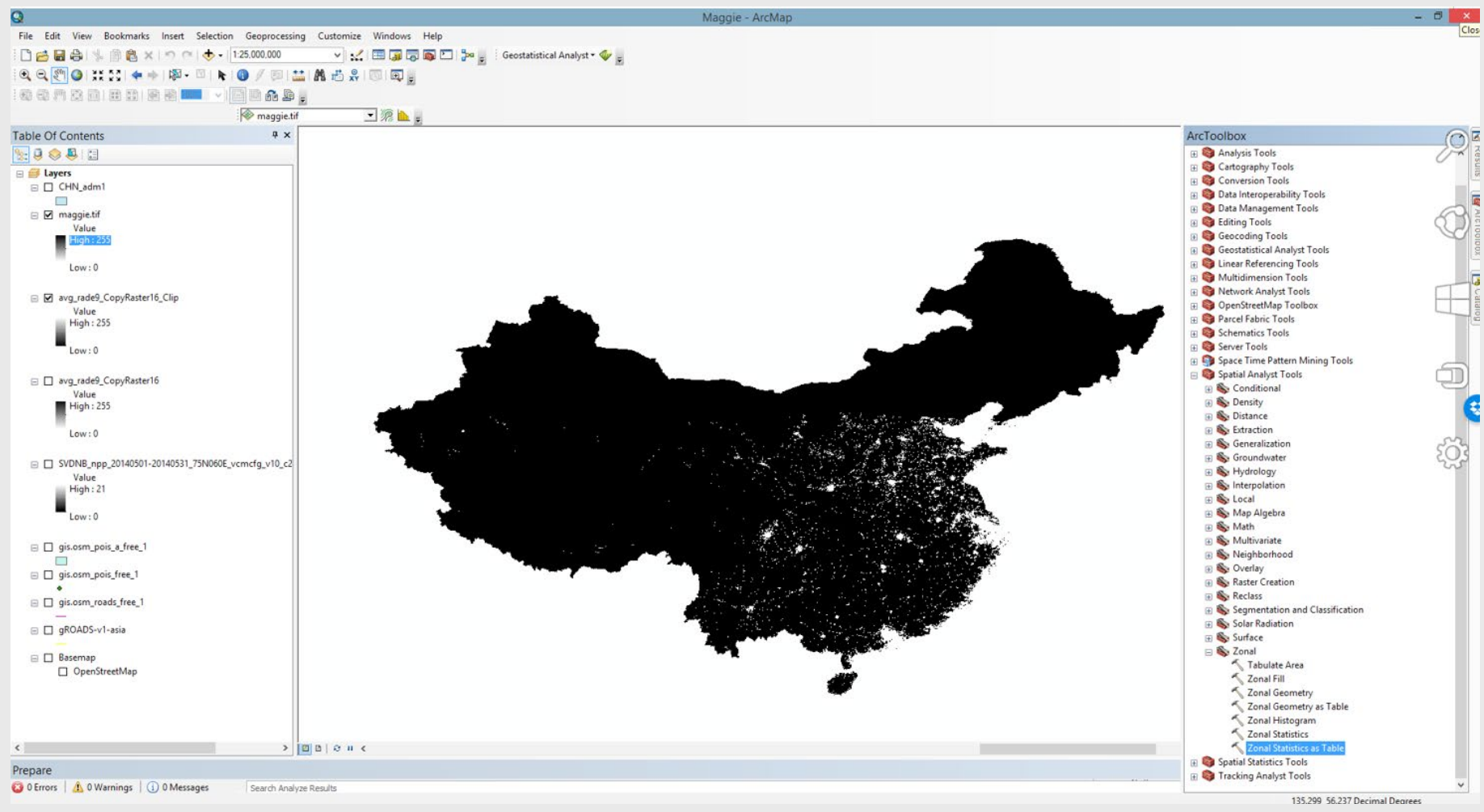

6. Extract the sum of radiances from the clip map called Maggie.tif by the CHN_adm1 and the NAME_1 of the provinces.

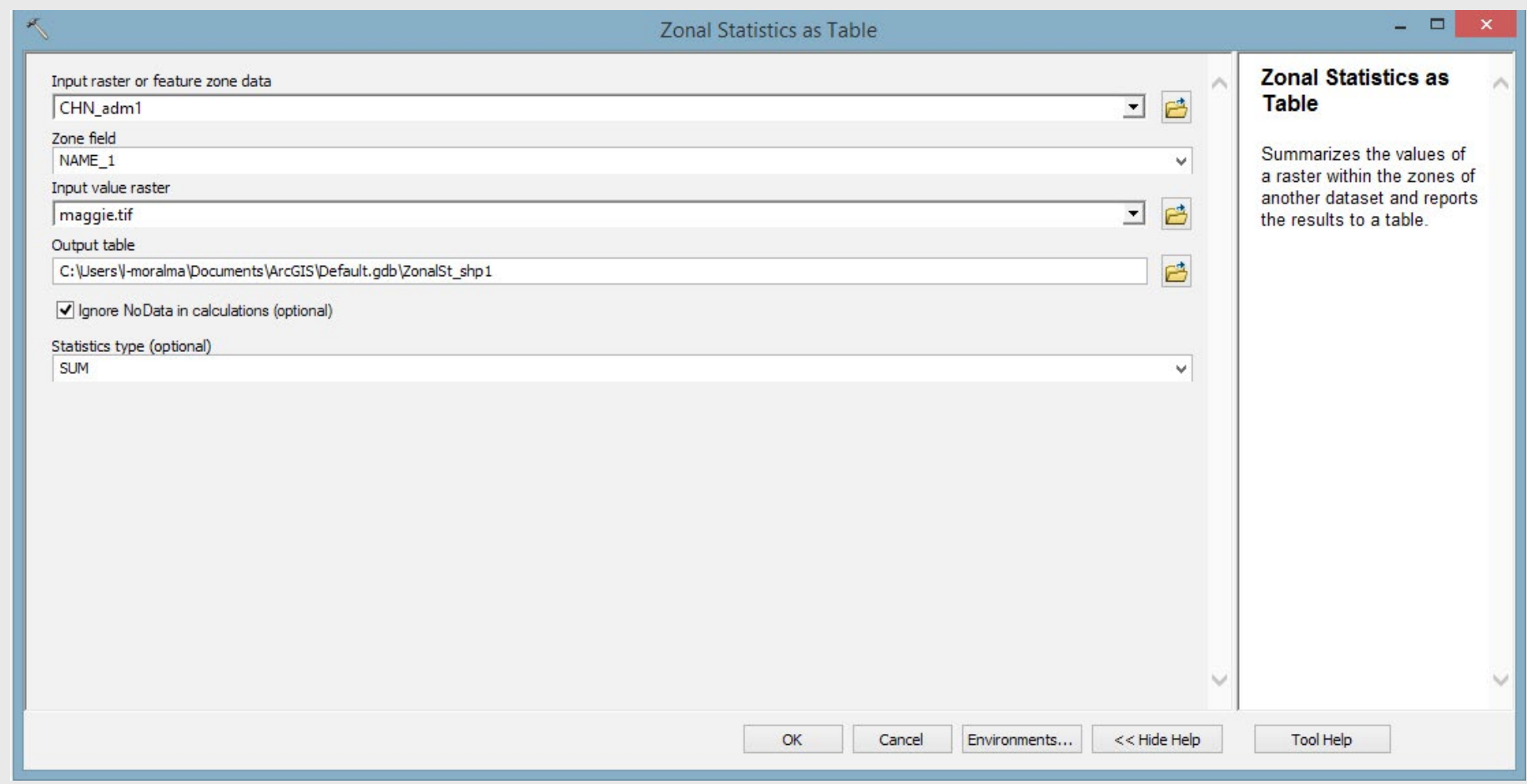


7. Export table.

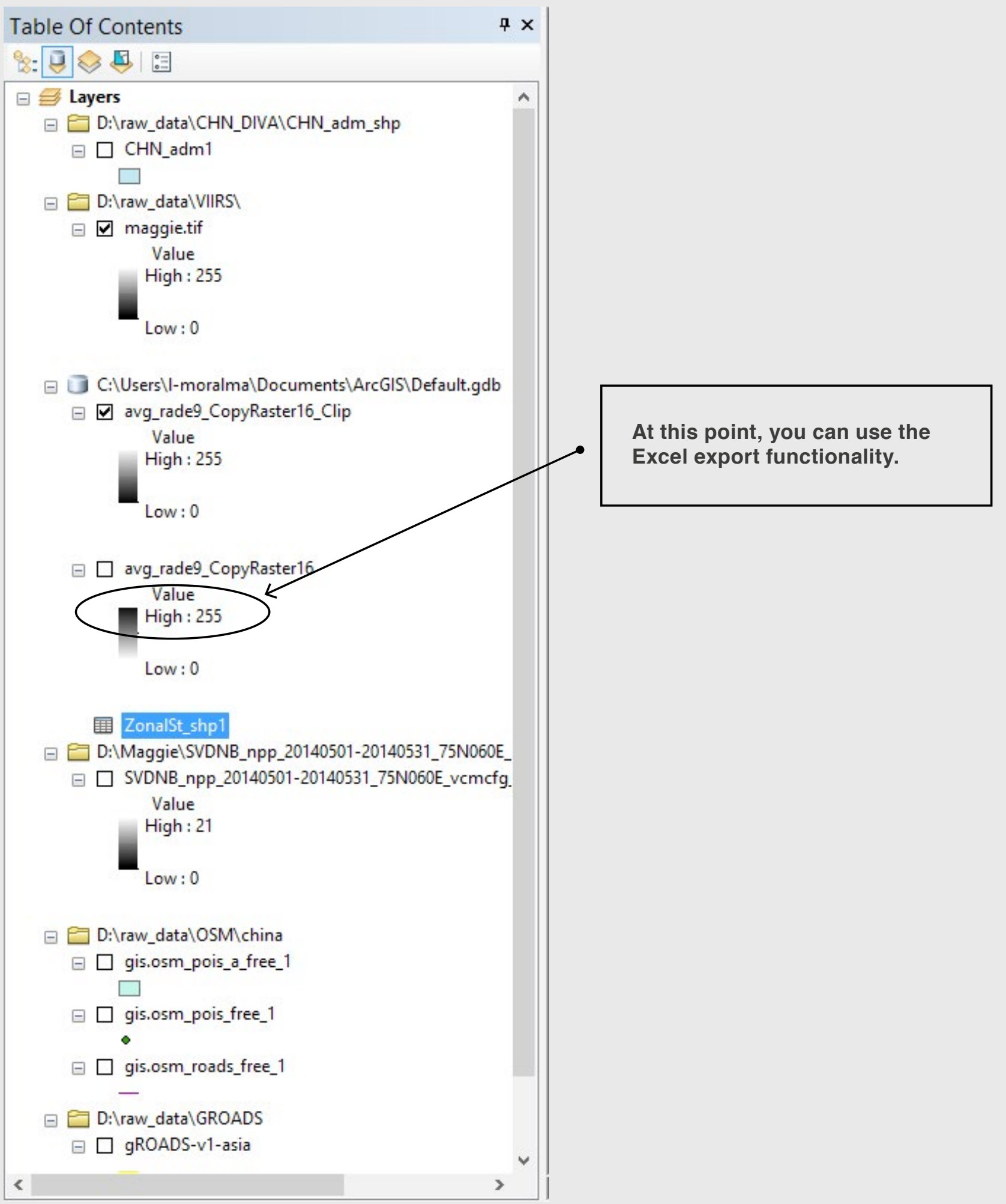


8. Conversion of Zonal Statistics table to Excel.

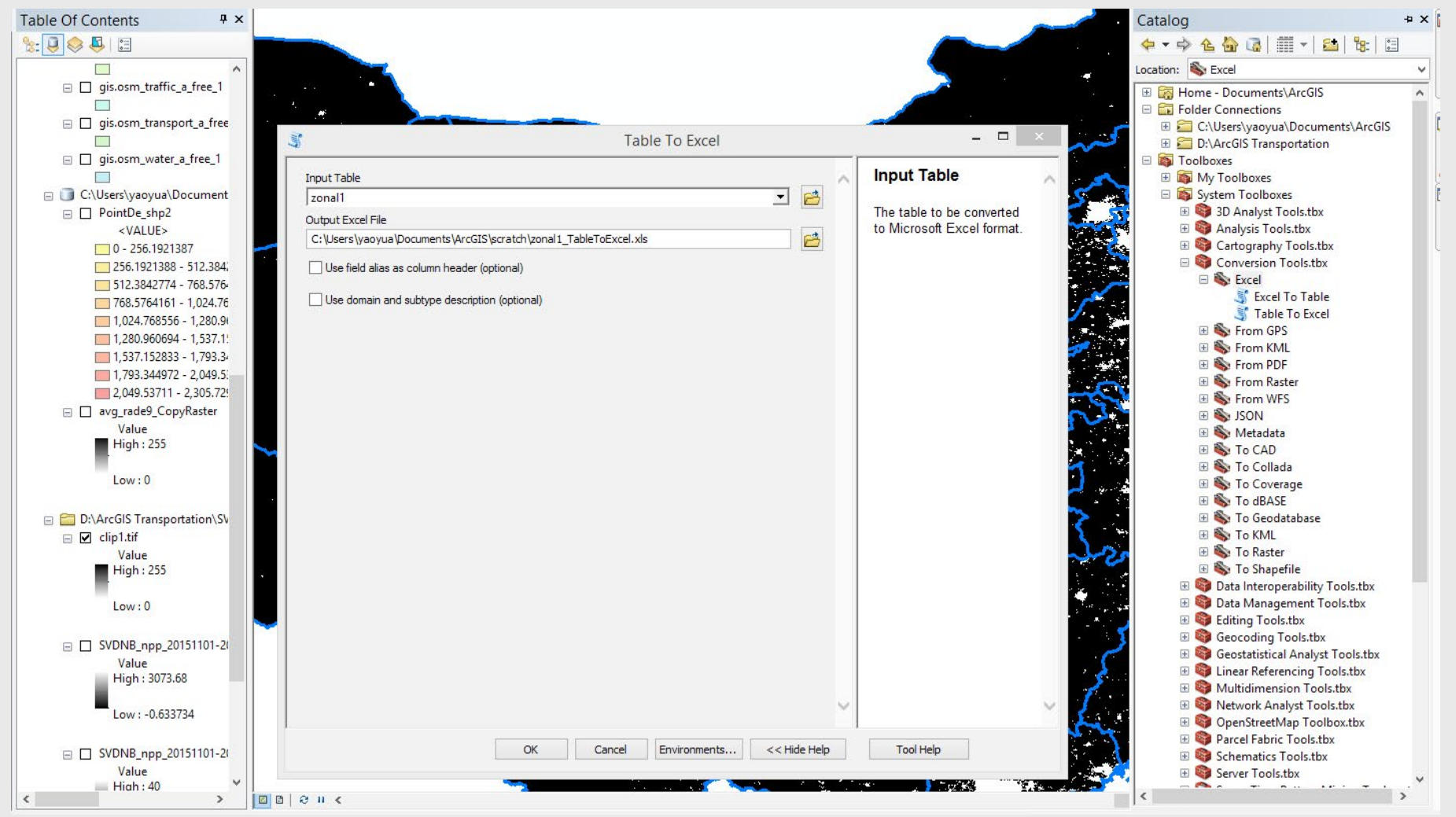




\section{Annex 2: Data on Freight Transportation Activity (FTA)}

Table 7. Data used for Chinese estimation.

\begin{tabular}{|c|c|c|c|c|}
\hline Province & FTA2012 (10K T) & FTA2013 (10K T) & FTA2014 (10K T) & FTA2015 (10K T) \\
\hline Beijing & 26161 & 25748 & 26551 & 20078 \\
\hline Tianjin & 46015 & 45233 & 49753 & 48779 \\
\hline Hebei & 219130 & 198009 & 209946 & 198024 \\
\hline Shanxi & 144607 & 156045 & 164918 & 161765 \\
\hline Nei Mongol & 189942 & 164346 & 191869 & 175112 \\
\hline Liaoning & 206788 & 206868 & 222138 & 202021 \\
\hline Jilin & 54808 & 44811 & 48311 & 43333 \\
\hline Heilongjiang & 65230 & 61094 & 60213 & 54478 \\
\hline Shanghai & 94038 & 84305 & 89980 & 90893 \\
\hline Jiangsu & 220007 & 181775 & 196153 & 198998 \\
\hline Zhejiang & 191817 & 188679 & 194250 & 201231 \\
\hline Anhui & 312436 & 396391 & 434298 & 345756 \\
\hline Fujian & 84345 & 96674 & 111757 & 111041 \\
\hline Jiangxi & 127195 & 135172 & 151878 & 130349 \\
\hline Shandong & 333602 & 264100 & 264459 & 261849 \\
\hline Henan & 272114 & 184823 & 200801 & 192859 \\
\hline Hubei & 122945 & 131000 & 150762 & 153904 \\
\hline Hunan & 191051 & 184535 & 203053 & 199716 \\
\hline Guangdong & 256076 & 349011 & 343491 & 339225 \\
\hline Guangxi & 161356 & 151143 & 163023 & 149714 \\
\hline Hainan & 26880 & 17325 & 23632 & 22287 \\
\hline Chongqing & 86474 & 87241 & 97377 & 103833 \\
\hline Sichuan & 174349 & 167759 & 159034 & 154597 \\
\hline Guizhou & 52654 & 72703 & 85672 & 84540 \\
\hline Yunnan & 68734 & 104329 & 108544 & 107608 \\
\hline Xizang & 1126 & 1850 & 1914 & 2125 \\
\hline Shaanxi & 136726 & 141579 & 157012 & 140900 \\
\hline Gansu & 45831 & 51463 & 57240 & 58251 \\
\hline Qinghai & 13483 & 13372 & 14638 & 15962 \\
\hline Ningxia Hui & 41113 & 40914 & 41308 & 42626 \\
\hline Xinjiang Uygur & 58793 & 66908 & 72168 & 70763 \\
\hline
\end{tabular}

Source: China Statistical Yearbook. 
Table 8. Data used for Indian estimation.

\section{STATE}

\begin{tabular}{l} 
Maharashtra \\
\hline Gujarat \\
\hline Andhra Pradesh \\
\hline Odisha \\
\hline Uttar Pradesh \\
\hline Madhya Pradesh \\
\hline Karnataka
\end{tabular}

Tamil Nadu

Punjab

Rajasthan

Jharkhand

West Bengal

Haryana

Delhi

Chhattisgarh

Kerala

Bihar

Assam

Himachal Pradesh

Jammu and Kashmir

Uttarakhand

Goa

Pondicherry

Meghalaya

Nagaland

Dagar and Nagar Haveli

Daman and Diu

Manipur

Mizoram

Tripura

Arunachal Pradesh

Chandigarh

Sikkim

Source: RITES.

FTA $2007 / 2008$ in T

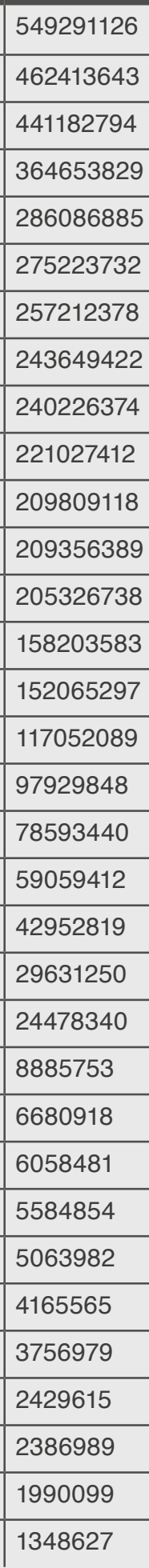


Table 9. Data used for Saudi Arabian estimation.

\begin{tabular}{|c|c|c|c|c|c|c|}
\hline Thousands of tonnes & $\begin{array}{l}\text { FTA } \\
2012\end{array}$ & $\begin{array}{l}\text { FTA } \\
2013\end{array}$ & $\begin{array}{l}\text { FTA } \\
2014\end{array}$ & $\begin{array}{l}\text { FTA } \\
2015\end{array}$ & $\begin{array}{l}\text { FTA } \\
2016\end{array}$ & $\begin{array}{l}\text { FTA } \\
2017\end{array}$ \\
\hline Riyadh & 160,267 & 223,549 & 232,379 & 174,047 & 204,945 & 198,309 \\
\hline Makkah & 144,817 & 133,805 & 161,043 & 215,159 & 154,387 & 152,780 \\
\hline Medina & 45,718 & 44,017 & 54,185 & 52,978 & 39,374 & 29,440 \\
\hline Qassim & 10,314 & 17,571 & 15,445 & 12,528 & 15,906 & 15,158 \\
\hline Eastern province & 416,704 & 378,683 & 376,645 & 435,865 & 472,734 & 435,009 \\
\hline Asir & 10,738 & 9,023 & 15,850 & 12,310 & 15,856 & 16,315 \\
\hline Tabuk & 6,744 & 8,335 & 6,998 & 12,102 & 11,245 & 9,475 \\
\hline Hail & 9,472 & 10,789 & 9,887 & 9,373 & 6,381 & 6,589 \\
\hline Northern border & 13,563 & 13,901 & 11,687 & 14,013 & 7,670 & 5,918 \\
\hline Jazan & 15,872 & 15,194 & 14,100 & 9,982 & 11,754 & 7,552 \\
\hline Najran & 8,797 & 9,796 & 8,267 & 8,827 & 7,236 & 6,403 \\
\hline Al-Baha & 8,746 & 8,537 & 9,733 & 8,585 & 3,962 & 2,798 \\
\hline Al-Jouf & 9,792 & 9,273 & 22,060 & 11,696 & 4,926 & 3,773 \\
\hline
\end{tabular}

Source: GaStat. 


\section{About the Authors}

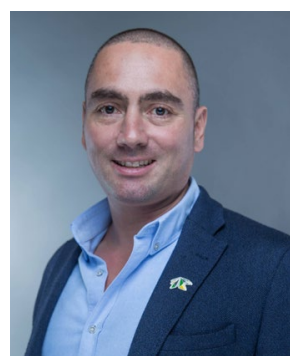

\section{Hector G. Lopez-Ruiz}

Hector is a research fellow specializing in transportation economics. He holds a Ph.D. in Economics from the University of Lyon.

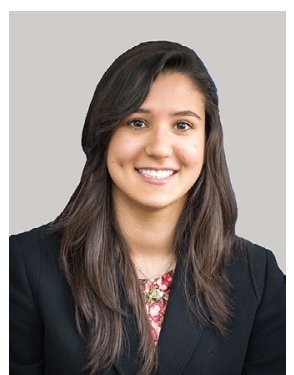

\section{Nora Nezamuddin}

Nora is a research associate focusing on energy in transportation and transport economic modeling. She has also worked on renewables transition policy and costs and its effects on electricity markets. She holds a B.S.B.A. in Business Administration and International Relations from The American University in Washington, D.C.

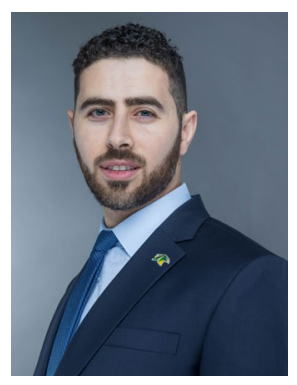

\section{Abdelrahman Muhsen}

Abdelrahman is a research associate and a certified GIS Professional (GISP). He holds an M.Sc. in Geomatics Engineering from the University of Calgary, Canada. His research interests focus on transportation, spatial analytics and geo-information management.

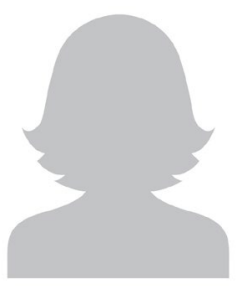

\section{Reema Alhassan}

Reema is a software engineer, focusing on system development life cycle. She holds a bachelor's degree in software engineering from King Saud University, Riyadh.

\section{About the Project}

The KAPSARC Transport Analysis Framework (KTAF) studies and models global economic activity and freight transportation. For this, KTAF relies on open-source global data from satellites and the spatial distribution of different economic activities by broad sectors. The main objective of KTAF is to offer quantified insights into the effects of policy measures on transportation activities and energy consumption related to freight mobility. 
INAPSARC

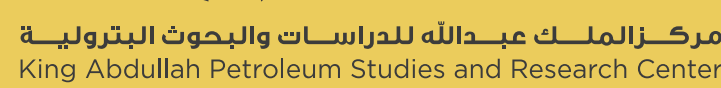

www.kapsarc.org 